\title{
A short history of climate change
}

\author{
DiRK Notz
}

Institute for Marine Research, University of Hamburg and Max Planck Institute for Meteorology Hamburg, Germany

Summary. - The flux of energy through the climate system determines the living conditions of our planet. In this contribution, I outline the main processes regulating this flux of energy, how these processes have changed throughout Earth history, and how today they are changing by human activities, in particular by activities related to energy production. The changes in the climate state of our planet, which have been ongoing ever since the formation of the Earth some 5 billion years ago, have shaped the world we live in today. Yet, today's climate change is special in two overarching ways. First, it is the first time that a major climate change is globally affecting a civilisation that is perfectly adapted to thousands of years of stable climate conditions. Second, today's climate change is occurring at a rate much faster than preceding natural climate changes. In combination, these two factors make today's climate change a unique challenge to humankind, with direct consequences of future energy production as outlined in the other contributions to this volume.

\section{1. - Introduction}

About 5 billion years ago, in some random location of our universe, a star was created by some random fluctuation of interstellar matter. A star, not very special, not very big, a star just like millions and millions of other stars that have come and gone throughout the existence of our universe. And yet, there was something special about this star: next to it, a planet formed whose properties allowed for the existence of liquid water. And this liquid water made this planet a unique place: The only known location of the entire universe that we know for sure is carrying life today. 
The liquid water on this planet owes its existence to a perfectly fitting combination of the main factors that determine the planet's temperature: First, the net amount of shortwave radiation around the wavelength of visible light that the planet receives from its central star. Second, the amount of longwave radiation (or heat radiation) that the planet's surface receives from its atmosphere. By changing either of these two factors, the climate of this planet has changed throughout the history of its existence. In this contribution, I will outline these changes in some detail and put them into the context of today's climate change on this planet, our Earth, whose stable climate condition over the past thousands of years have been crucial for the development of our human civilisation. I will start with a short overview of the functioning of the climate system of our planet, will then move on to briefly outline some of the past changes of the mean climate state, and will finally describe the climate change that we humans are causing today and its possible implications for the future.

\section{2. - The climate system of our planet}

The functioning of the climate system of our planet is governed by the flux of energy, with three specific fluxes being most important: First, the flux of energy from the sun to the Earth. Second, the reflection of some of this energy. And third, the flux of energy from the atmosphere to the surface and to outer space (fig. 1).

In thermal equilibrium, the energy that the Earth receives from the sun must be balanced by an equal loss of energy from the Earth to space. On average, the Earth receives today across its cross section about $1360 \mathrm{~W} / \mathrm{m}^{2}$ of energy from the sun. Because the surface area of the Earth is four times as large as its cross section, each square meter of the Earth's surface receives on average about $340 \mathrm{~W}$ of energy from the sun, primarily as so-called shortwave radiation, which describes radiation with wavelengths in the visible, near-infrared and near-ultraviolet spectra.

About a third of this energy is reflected back to space by clouds and the Earth's surface. Their reflectivity is referred to as albedo, which varies widely depending on surface and cloud conditions. For example, the albedo of the open ocean can be below $10 \%$, i.e. more than $90 \%$ of the incoming solar radiation is absorbed. In contrast, the albedo of freshly fallen snow can be above $80 \%$, implying that only $20 \%$ of the incoming solar radiation is absorbed with the remainder being reflected to space.

With about a third of the incoming $340 \mathrm{~W} / \mathrm{m}^{2}$ being reflected to space, slightly more than $200 \mathrm{~W} / \mathrm{m}^{2}$ of energy must leave the Earth by other means to achieve thermal equilibrium. These "other means" are achieved by the Earth radiating heat, or long-wave radiation to space. To radiate about $200 \mathrm{~W} / \mathrm{m}^{2}$, according to the Stefan Boltzmann law, a body must have a temperature of about $-18{ }^{\circ} \mathrm{C}$. Without an atmosphere, this would be the surface temperature of our planet if its albedo were the same as today. In reality, however, without an atmosphere the temperature of the planet would be much lower than this number, because it would be frozen over and reflect most incoming solar radiation directly back to space. 


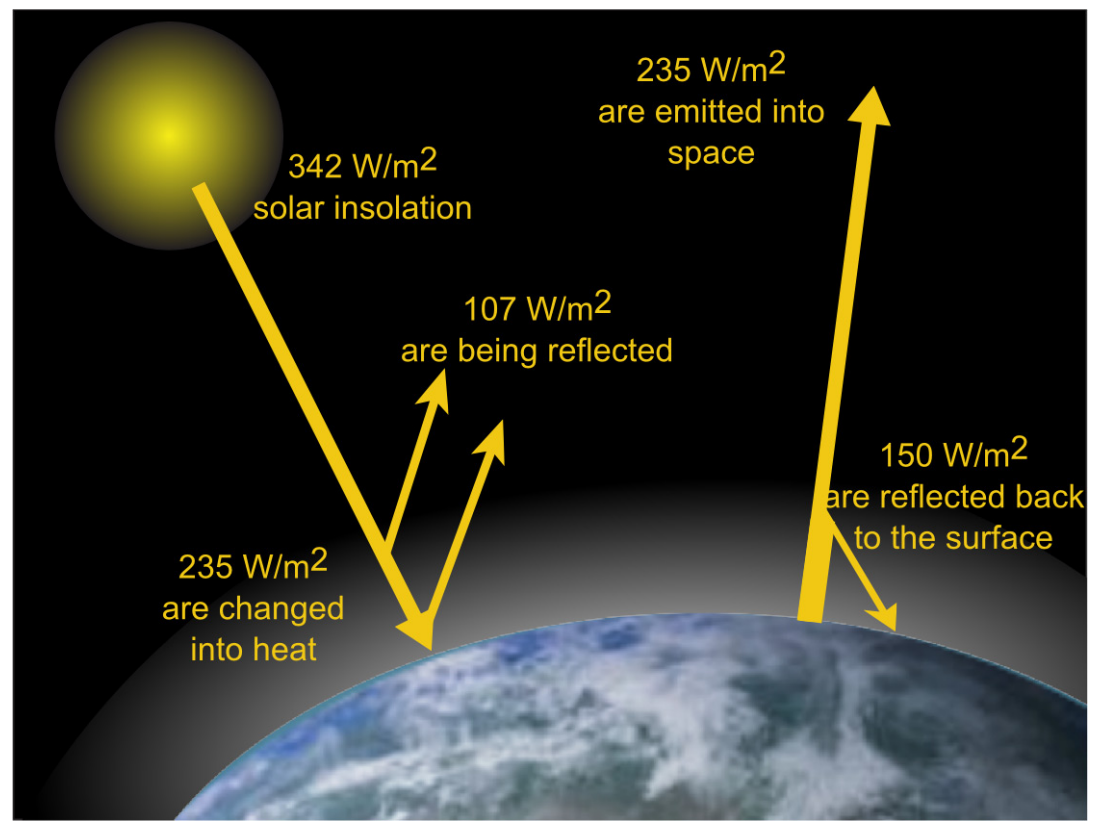

Fig. 1. - The average energy budget of the Earth.

However, because the Earth has an atmosphere that is able to emit long-wave radiation, the temperature of $-18^{\circ}$ that is necessary to compensate for the incoming solar radiation is not manifested at the Earth surface, but instead at some higher level in the atmosphere. Hence, in the longwave spectrum, seen from outer space one does not see the temperature of the Earth surface, but instead the temperature of the atmosphere at some level high above the ground.

The fact that the atmosphere is not translucent for long-wave radiation, but instead is able to emit long-wave radiation itself, is primarily owing to the existence of so called trace gases in the atmosphere. The main atmospheric constituents, i.e. nitrogen $(78 \%)$, oxygen $(21 \%)$ and argon $(0.93 \%)$ barely interact with radiation in the long wave spectrum. Hence, by far most of the emission of the atmosphere in the long wave spectrum stems from radiatively active trace gases, in particular water vapour, carbon dioxide and methane.

Because of the existence of these trace gases in the atmosphere, the surface temperature of our planet is today about 14 to $15^{\circ} \mathrm{C}$ rather than $-18^{\circ} \mathrm{C}$, because the trace gases do not only radiate energy upwards into space, but also downward to the surface. The best known manifestation of this heat radiation from the atmosphere is experienced at night time, where a clear night is much colder than a cloudy night because a cloudy atmosphere radiates more heat towards the surface. But even without clouds, the fact that our planet's surface temperature during night does not drop to outer space conditions is primarily achieved through the longwave radiation from the atmosphere to the surface. 
While this description is slightly simplified, it nevertheless allows us to understand the three main processes by which the climate conditions of our planet can be changed. First, by changes in incoming solar radiation. Second, by changes in the planetary albedo and thus by changes in outgoing solar radiation. And third, by changes in atmospheric condition that changes the upward and downward flux of longwave radiation through the atmosphere. Throughout the history of our planet, these three factors have always been changing. Hence, climate change is as old as the history of the Earth, as described in the following. Understanding such natural climate change is crucial for appreciating the uniqueness of today's man-made climate change that we focus on afterwards.

\section{3. - Climate change throughout Earth's history}

Since the formation of the Earth some 5 billion years ago, the factors determining its climate state have been changing repeatedly. For example, the young sun was shining about $30 \%$ weaker than it does today, limiting the amount of shortwave radiation reaching the Earth. Nevertheless, the young Earth was sufficiently warm to allow for the existence of liquid water. The necessary warming possibly came from a greater amount of greenhouse gases in the atmosphere compared to today, but the "faint-sun" problem is not finally settled [1].

Some billion years later, in contrast, the Earth was much colder than it is today. There is ample evidence that about 650 million years ago, the Earth was covered in ice for many million years (e.g., [2]). A key factor in reaching this state was probably the fact that the location of most land masses was much closer to the equator than it is today. Because of this, land on average received more precipitation. This, in turn, caused increased weathering of rock, binding atmospheric carbon dioxide as lime. Hence, the atmospheric concentration of greenhouse gases decreased, the Earth cooled, and froze over more and more. Once substantial amounts of ice had formed, the increasing reflection of incoming sun light caused further cooling and more ice formation, perpetuating the snowball-state most likely for many million years. At some point, however, the Earth was able to warm again, possibly through the emission of greenhouse gases from volcanic eruption, the ice cover decreased, less sun light was reflected, and the snowball period ended.

Later in Earth's history, our planet was much warmer than it is today. For example, some hundred million years ago, when dinosaurs were dominating the biosphere, global average temperature was about $14^{\circ} \mathrm{C}$ higher than today. Such warm temperature was primarily related to much higher atmospheric carbon dioxide concentration, and the absence of any reflective ice or snow cover (e.g., [3]). While the precise concentration of carbon dioxide is still being debated, it most likely was higher than 1000 parts per million, compared to 280 parts per million 200 years ago and around 400 parts per million today. Levels of $\mathrm{CO}_{2}$ concentration exceeding 1000 parts per million are still experienced today - namely in indoor setting with poor ventilation. $\mathrm{CO}_{2}$ concentrations above this $1000 \mathrm{ppm}$ are usually considered as a threshold for poor performance, and should hence be avoided in offices and schools. Nevertheless, physiologically, humans can survive such high $\mathrm{CO}_{2}$ concentration in principle. 


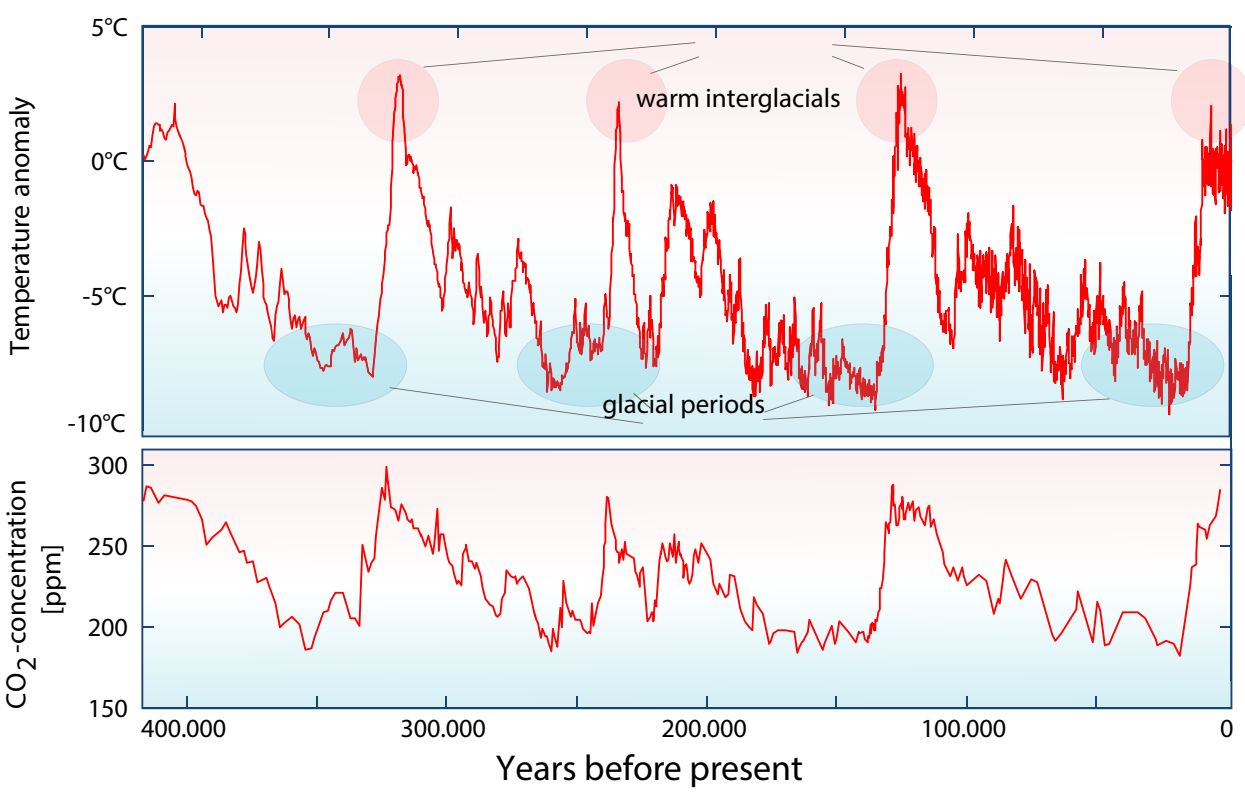

Fig. 2. - Fluctuations of Earth temperature and atmospheric $\mathrm{CO}_{2}$ concentration over the past 400000 years, from the Vostock ice core.

Since that hot period 100 million years ago, $\mathrm{CO}_{2}$ concentration in the Earth atmosphere has slowly decreased, causing a slow cooling of our planet. The cooling caused the formation of ice sheets in the Antarctic probably some 50 million years ago and in the Northern hemisphere some 10 million years ago. These ice masses then reflected sun light and caused some additional cooling of the Earth climate. Around 1.5 million years ago, the cooling of our planet then finally initiated the so-called ice-age cycle, which caused the Earth's climate to fluctuate quite regularly between periods of wide-spread coverage of high latitudes with glaciers during an ice age, and intermediate periods with retreating glaciers and warmer temperatures such as today's Holocene period (fig. 2).

We have very reliable measurements of these fluctuations from ice cores in Greenland and in the Antarctic. Both these ice sheets have formed from snow, such as any other glacier. If temperatures are sufficiently low for the snow to never melt, over long periods the snow cover eventually becomes so thick that it is transformed into ice from the pressure of its own weight. Hence, if one stands on top of, say, Greenland and drills into depth, the ice that one drills through has formed from snow that fell hundred years ago, thousand years ago, hundred thousand years ago. In the ice, still bubbles of air from that period are enclosed, whose analysis allows scientists to reconstruct time series of atmospheric composition. An analysis of the isotopic composition of the ice, in turn, allows for a reconstruction of atmospheric temperature, as in cold conditions a higher fraction of lighter water isotopes will be contained in the ice core.

The temperature fluctuations that were identified this way are today understood as being a direct consequence of all the three main factors that influence the climate of 
the Earth. First, the orbit of the Earth around the sun fluctuates regularly, causing northern hemisphere summer temperatures to be, for example, slightly colder roughly every hundred thousand years. Because of these cool summers, glaciers on land in the northern hemisphere will slightly expand, causing some extra cooling. Because of this cooling, the oceans become colder as well. Cold water, however, can absorb more carbon dioxide than warm water, and the oceans will take up carbon dioxide from the atmosphere to maintain chemical equilibrium. This then causes a drop in atmospheric $\mathrm{CO}_{2}$ concentration, which causes additional cooling, further expansion of glaciers and more reflection of solar radiation. The Earth enters an ice age. At some point, the Earth's orbit has changed again, solar radiation during summer in the Northern hemisphere increases slightly, glaciers retreat, the Earth warms, and the oceans release carbon dioxide into the atmosphere. Because the oceans are warmed at their surface, they are stably stratified, and their warming and the accompanying release of carbon dioxide into the atmosphere occur much faster than the initial uptake. This is one explanation for why ending an ice age usually occurs much faster than its onset.

This brief overview just goes to illustrate that climate change has been a constant companion of our planet. We could not understand the world as it looks today without these past changes. Nevertheless, today's climate change is unique in many ways, as we will see in the following.

\section{4. - Today's climate change}

As we have just seen, climate change has always occurred throughout the history of our planet. It is hence quite unusual that for the past 10000 years, the climate conditions of the Earth were very stable, as we see for example from ice core records in Greenland (fig. 3). This period of stable conditions was used by humans to develop their modern civilisation: about 5000 years ago, humans slowly moved from the Stone Age to the Bronze Age, and then trough the Iron Age towards our modern civilisation. Much of this development was only possible because the climatic boundary conditions were comparably stable. Hence, large cities could develop with their location being compatible with the sea-level associated to this stable climate. Agriculture could develop because the large-scale patterns of precipitation and temperature were comparably stable. The kind of houses people lived in, their trade routes, the number of people that could live in a given community etc. are all condition to climate conditions. And because these climate conditions were stable, civilisation was able to develop largely undisturbed globally. Regionally, changes in climate have most likely repeatedly contributed to the disappearance of ancient cultures, but globally the development of civilisation was able to continue.

Hence, a major distinguishing feature of the ongoing climate change is the fact that for the first time, all of our human civilisation is globally affected by a large scale climate change of a magnitude unknown throughout the past 10000 years of human development. The ongoing climate change is an experiment to understand how a civilisation that was able to develop without major climate change for thousands of years will react if it suddenly is exposed to a rapid shift in climate conditions, occurring over the period of just a few decades. 


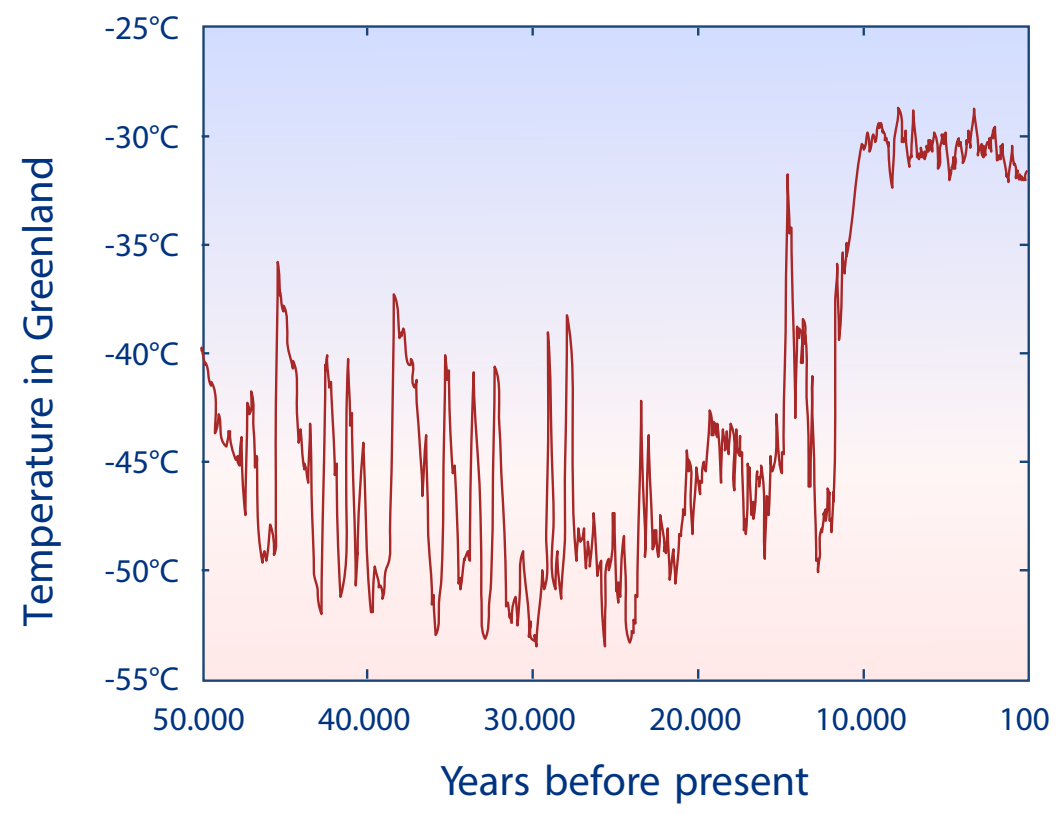

Fig. 3. - Fluctuations of the temperature in Greenland over the past 50000 years, from the GISP2 ice core.

This, in turn, is the second distinguishing feature of modern climate change: The rapidity of the ongoing warming and of the ongoing rise in atmospheric carbon dioxide conditions, both occurring much faster than the natural changes of the past millions of years, in particular as the changes today appear on a global scale. Hence, while eco systems have often been able to adapt to the slow changes of the past, it is unclear how they can adapt to the rapid changes that we humans are causing today. Note that regionally, rapid changes have occurred in the past. For example, the North-Atlantic region has been influenced by so-called Dansgaard-Oeschger events that cause the temperature fluctuations in the Greenland temperature record shown in fig. 3.

The fact that climate change is occurring is clear. For example, the global temperature of the past five years was the highest since the beginning of the instrumental record. The extent of sea ice in the Arctic Ocean in the past few years has been the lowest since most likely at least 1000 years. The melting of glaciers is accelerating, which indicates that this melt is no longer just a response to the slow ending of the past ice age, but is to a substantial degree driven by the ongoing warming of our planet. Sea level is rising faster and faster, currently at a rate of about 4 millimetres per year. Permafrost is melting, spring snow coverage decreases (see [4] for all the above). Taken together, all these indicators clearly show that the climate of our planet is changing rapidly.

However, given that climate change has always occurred even before the existence of human civilisation, how can we be so sure that most of this change is caused by human activities? The answer is very simple: We can be so sure because there is an overwhelming 


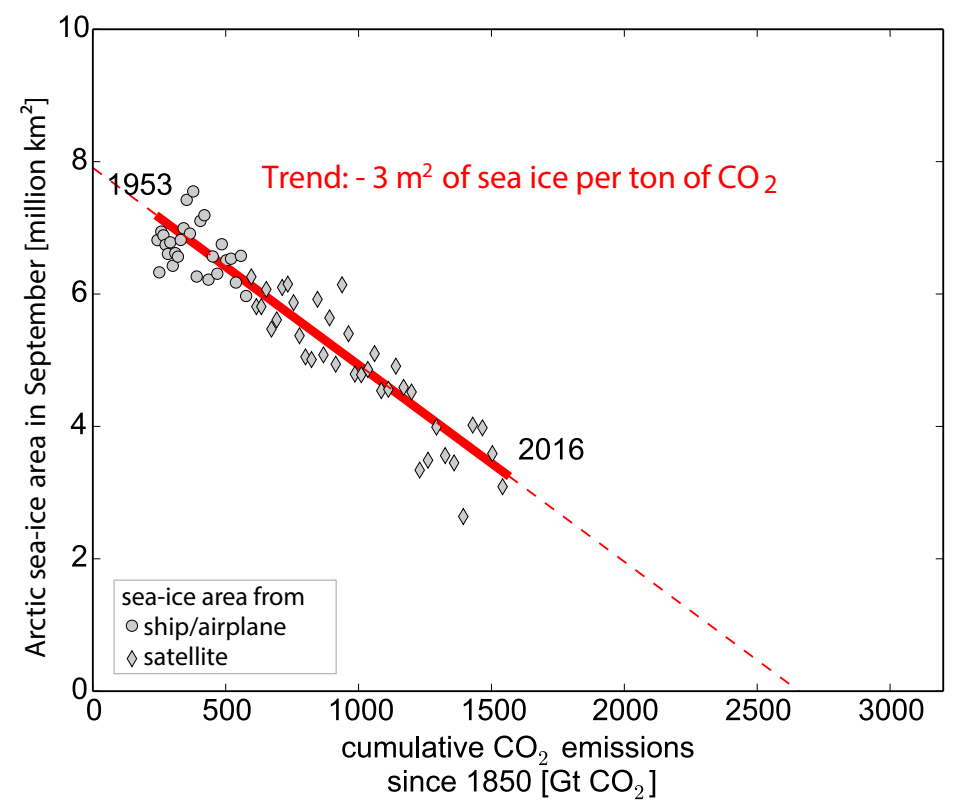

Fig. 4. - Relationship between anthropogenic $\mathrm{CO}_{2}$ emissions and Arctic sea-ice area in September.

multitude of scientific publications that have again and again shown that no other factor that influences the climate of our planet has changed sufficiently much over the past decades to explain the ongoing changes, including in particular natural fluctuations of the climate system. For example, if we force a climate model, which is a computer program representing our knowledge of atmosphere, ocean and ice, with the observed changes in natural drivers such as solar activity and volcanic eruptions, every single existing climate model will provide an evolution of past climate with no distinguishable warming over the past few decades. It is not possible to simulate the ongoing warming in any model representation of our physical understanding of the climate system if we only consider natural forcing. In contrast, if we add the observed change in atmospheric $\mathrm{CO}_{2}$ composition to such simulation, the simulated climate evolution is compatible with the observational record. Because we know from budget analyses of fossil-fuel burning and from isotopic analyses of atmospheric $\mathrm{CO}_{2}$ that humans have caused the observed increase in atmospheric $\mathrm{CO}_{2}$ concentration, we can infer that "it is extremely likely that human influence has been the dominant cause of the observed warming since the mid-20th century" [5].

Many other lines of evidence exist to show the clear contribution of human activities to the ongoing changes. For example, there is a clear correlation between observed Arctic sea-ice area and anthropogenic $\mathrm{CO}_{2}$ emissions (fig. 4). A similar correlation is found in all climate-model simulations, suggesting an underlying physical causality causing the linear relationship. Such causality can indeed be derived from the energy balance at the sea-ice edge that moves northward as the atmospheric longwave radiation increases 
until the northward decrease in solar shortwave radiation has compensated for the additional warming from the long-wave radiation. Because we have three independent lines of evidence, namely observational record, climate model simulations, and conceptual understanding, it is clear that the identified linear relationship is not merely a correlation, but indeed a consequence of the causal relationship of anthropogenic $\mathrm{CO}_{2}$ emissions and Arctic sea-ice loss. The slope of the linear relationship suggests that about $3 \mathrm{~m}^{2}$ of Arctic sea ice in September are lost for each ton of $\mathrm{CO}_{2}$ emissions from anthropogenic activities. Hence, depending on our individual carbon foot print of usually between 5 and 10 tons per year, each of us melts some 15 to $30 \mathrm{~m}^{2}$ of Arctic sea ice every single year. In addition, this very simple relationship also holds an additional truth: The melting of Arctic sea ice, and the ongoing warming of our planet, will only stop if net $\mathrm{CO}_{2}$ emissions are decreased to zero. As long as net $\mathrm{CO}_{2}$ emissions are above zero, the planet will become warmer and warmer. This then, finally, allows for a short glimpse into the possible future, which will form the final section of this short overview.

\section{5. - A future of possibilities}

The fact that we humans are the main driver of today's climate change implies that also the future evolution of the climate system of the Earth will largely depend on our decisions. Currently, humans emit about 40 billion tons of $\mathrm{CO}_{2}$ into the atmosphere every single year. About half of these $40 \mathrm{Gt}$ stay in the atmosphere, about a quarter is taken up by the oceans causing ocean acidification, and the final quarter is taken up by the global ecosystem and land masses. Other anthropogenic forcers of the climate system are of secondary importance, including the cooling impact of aerosols (e.g., soot) and the additional warming impact of other greenhouse gases such as methane. Because of this secondary importance, because of the relatively short time scales involved, and because of a largely linear relationship between global temperature evolution and $\mathrm{CO}_{2}$ emissions, the concept of carbon budgets has been widely accepted as a measure of expected future warming levels. These carbon budgets give the amount of carbon dioxide that may still be emitted to keep global warming below a certain level by the end of this century.

Regarding the specific levels of global warming, in particular the thresholds of $1.5^{\circ} \mathrm{C}$ and $2.0^{\circ} \mathrm{C}$ are of importance, because the internationally binding Paris agreement calls for the world's countries to limit the negative impact of global warming by "holding the increase in the global average temperature to well below $2{ }^{\circ} \mathrm{C}$ above pre-industrial levels and pursuing efforts to limit the temperature increase to $1.5^{\circ} \mathrm{C}$ above pre-industrial levels, recognising that this would significantly reduce the risks and impacts of climate change". Currently, the global average temperature is about $1.1^{\circ} \mathrm{C}$ above pre-industrial levels, implying roughly a factor two in the remaining warming allowable for the $2.0^{\circ} \mathrm{C}$ target compared to the $1.5^{\circ} \mathrm{C}$ target.

While the difference between these two warming levels looks small, there is a qualitative difference in the likely response of the Earth System to the two warming levels [6]. For example, if global warming remains below $1.5^{\circ} \mathrm{C}$, the Arctic Ocean will remain seaice covered all year round in the vast majority of years. In contrast, for $2.0^{\circ} \mathrm{C}$ global warming, the Arctic Ocean will usually be sea-ice free in summer. More importantly, 
however, at $1.5^{\circ} \mathrm{C}$ global warming, the Greenland ice sheet will most likely remain stable, and its potential melting is reversible if temperature were to decrease again. At $2.0^{\circ} \mathrm{C}$ global warming, in contrast, chances are large that the Greenland ice sheet will become unstable, and its complete melting can not be stopped any more, even if temperature were to decrease again. Such complete melting of the Greenland ice sheet would raise global sea levels by about 7 metres over the next centuries and millennia. The irreversibility of the ice loss is primarily related to the fact that melting of the Greenland ice sheets at its surface lowers the elevation of the ice sheet. Hence, the surface is exposed to the warmer temperature of lower-lying air masses, similar to the warming one experiences when walking down a mountain. These warmer air masses will then cause increased melting, and the surface elevation is decreased further.

Similarly, chances are substantial that for $2.0^{\circ} \mathrm{C}$ global warming parts of the Antarctic ice sheet become unstable and their complete melting can no longer be stopped either. Again, this would cause several metres of unavoidable sea-level rise over time scales of centuries and millennia. The irreversible melting of the Antarctic ice sheet is related to the slow outflow of the ice sheet into the ocean. The amount of ice lost by this outflow is closely related to the thickness of the ice sheet at the so-called grounding line, i.e. at the line where the ice sheet becomes free-floating in the ocean. Crucial for the instability is the fact that the bottom topography of the land masses underneath the ice shelf slopes downward towards the South pole in many regions. Hence, if the ocean warms, causing ice melt at the grounding line and thus a retreat of the grounding line towards the South pole, the ground lowers further and further, causing more and more ice loss. This increased ice loss than causes a further retreat of the grounding line towards the pole, and thus additional, irreversible ice loss.

These are but some of the reasons why the Paris agreement calls the world's countries to pursue efforts to keep global warming below $1.5^{\circ} \mathrm{C}$. To reach this aim with a likelihood of $67 \%$, current best estimates of the remaining carbon budget lie at around $340 \mathrm{Gt} \mathrm{CO}_{2}$ additional emissions from 1st January 2020. At current emission levels of around $40 \mathrm{Gt}$ $\mathrm{CO}_{2}$ per year, this budget will be used up in about 8 years. Hence, to limit global warming to below $1.5^{\circ} \mathrm{C}$, the global $\mathrm{CO}_{2}$ emissions must decrease extremely quickly. How this can potentially be achieved in the energy sectors, and which difficulties one faces in doing so, is discussed in some of the other chapters of this volume. In addition, almost all trajectories that have been suggested to allow for a limitation of global warming to below $1.5^{\circ} \mathrm{C}$ at some point imply negative emissions. Hence, $\mathrm{CO}_{2}$ must be removed from the atmosphere and stored somewhere to reverse a possible overshoot of future $\mathrm{CO}_{2}$ emissions above the limit of $340 \mathrm{Gt}$. Such $\mathrm{CO}_{2}$ removal could for example occur by having quickly growing plants converting $\mathrm{CO}_{2}$ from the atmosphere into biomass. By burning this biomass, one gains heat and pure $\mathrm{CO}_{2}$ which then must be stored. This is referred to as "bio-energy with carbon capture and storage" (BECCS). However, current estimates of the required land area that would be needed to remove the envisioned $10 \mathrm{Gt}$ of $\mathrm{CO}_{2}$ from the atmosphere per year are about a third the size of Europe.

In summary, it is clear that the climate of our planet is currently changing at a very rapid rate. It is clear that this warming will cause a climate change of a scale 
never experienced by human civilisation. It is clear that human influence has been the dominant cause of the observed warming. And it is clear that the climate will continue to warm as long as additional net $\mathrm{CO}_{2}$ is added to the atmosphere. It is, however, much less clear how quickly we humans will be able to reduce net- $\mathrm{CO}_{2}$ emissions to near zero. Some of the challenges in this respect, and some of the possible ways forward are laid out in other contributions to this volume.

\section{REFERENCES}

[1] Feulner G., "The faint young Sun problem", Rev. Geophys., 50 (2012) RG2006, doi: 10.1029/2011RG000375.

[2] Hoffman P. F. et al., "Snowball earth climate dynamics and cryogenian geologygeobiology", Sci. Adv., 3 (2017) e1600983, doi: 10.1126/sciadv.1600983.

[3] Royer D. L., " $\mathrm{CO}_{2}$-forced climate thresholds during the phanerozoic", Geochim. Cosmochim. Acta, 70 (2006) 5665.

[4] IPCC, Special Report on the Ocean and Cryosphere (SROCC) (IPCC) 2019.

[5] Stocker T. et al. (Editors), Climate Change 2013: The Physical Science Basis. Contribution of Working Group I to the Fifth Assessment Report of the Intergovernmental Panel on Climate Change (Cambridge University Press, Cambridge, UK and New York, NY, USA) 2013.

[6] IPCC, Global warming of $1.5^{\circ} \mathrm{C}$ (IPCC) 2018. 